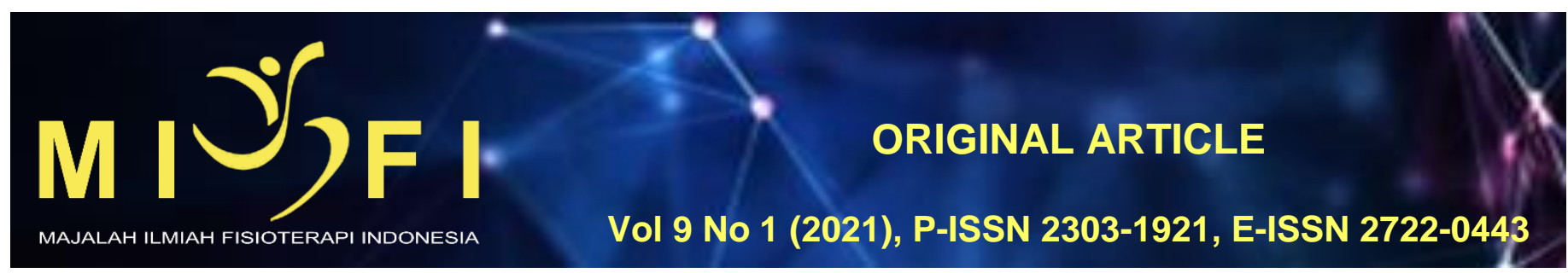

\title{
PEMBERIAN PILATES EXERCISE MENURUNKAN DERAJAT DISMENORE PRIMER PADA SISWI DI SMA NEGERI 3 DENPASAR
}

\author{
Rolyta Triasari Purba1, Putu Ayu Sita Saraswati ${ }^{2}$, Made Widnyana ${ }^{3}$, Luh Made Indah Sri Handari Adiputra ${ }^{4}$ \\ ${ }_{1}^{1}$ Program Studi Sarjana Fisioterapi dan Profesi Fisioterapi, Fakultas Kedokteran, Universitas Udayana, Denpasar, Bali \\ ${ }^{2,3}$ Departemen Fisioterapi, Fakultas Kedokteran, Universitas Udayana, Denpasar, Bali \\ ${ }^{4}$ Departemen IImu Faal, Fakultas Kedokteran, Universitas Udayana, Denpasar, Bali \\ rolytatriasari@gmail.com
}

\begin{abstract}
ABSTRAK
Menstruasi merupakan perdarahan akibat peluruhan dinding endometrium secara teratur pada seorang wanita yang tidak sedang hamil dan belum menopouse setiap bulannya. Saat menstruasi wanita banyak mengalami berbagai masalah, salah satunya dismenore primer. Terdapat suatu metode terapi latihan yang dapat digunakan sebagai metode preventif dan kuratif pada kondisi dismenore primer, yaitu pilates exercise. Penelitian ini bertujuan untuk mengetahui pengaruh pemberian pilates exercise dalam menurunkan derajat dismenore primer siswi di SMA Negeri 3 Denpasar. Studi eksperimental ini menggunakan desain control group pre test-post test. Sampel penelitian berjumlah 30 sampel dengan teknik purposive sampling. Terdapat kelompok perlakuan yang diberikan pilates exercise dan kelompok kontrol. Pilates exercise dilakukan 3x/seminggu selama 3 minggu. Derajat dismenore dinilai menggunakan NRS (Numerical Rating Scale) dan MMDQ (Modified Menstrual Distress Questionnaire). Rerata usia kelompok perlakuan dan kelompok kontrol adalah 16,40 tahun dan 16,53 tahun. Rerata IMT kelompok perlakuan dan kelompok kontrol adalah 21,76 kg/m² dan $21,41 \mathrm{~kg} / \mathrm{m}^{2}$. Hasil nilai uji hipotesis paired sample T-test pada MMDQ kelompok perlakuan adalah $\mathrm{p}=0,000$ $(p<0,05)$ dan kelompok kontrol $p=0,087(p>0,05)$. Pengukuran NRS kelompok perlakuan $p=0,000(p<0,05)$ dan kelompok kontrol $p=0,032(p<0,05)$. Hasil Independent sample T-test pada pengukuran MMDQ dan NRS menunjukkan $p=0,00(p<0,05)$. Dapat disimpulkan bahwa pemberian pilates exercise menurunkan derajat dismenore primer pada siswi di SMA Negeri 3 Denpasar.
\end{abstract}

Kata kunci: menstruation, dismenore primer, pilates exercise

\section{PILATES EXERCISE REDUCED DEGREE OF PRIMARY DYSMENORRHEA AT SMA NEGERI 3 DENPASAR}

\section{ABSTRACT}

Menstruation is bleeding due to regular shedding of endometrial wall in woman who is not pregnant and menopause that happen every month. During menstruation, women experience many problems, one of them is primary dysmenorrhea. There is an exercise therapy method that can help to prevent and cure primary dysmenorrhea, it's called pilates exercise. This study was purposed to determine the effectivity of pilates exercise in decreasing degree of primary dysmenorrhea for students at SMA Negeri 3 Denpasar. This experimental study was control group pre test - post test design. The research sample was 30 samples with purposive sampling technique. There were the treatment group and control group. The treatment group did pilates exercise 3 times/week for 3 weeks. The dysmenorrhea degree was assessed using NRS (Numerical Rating Scale) and MMDQ (Modified Menstrual Distress Questionnaire). The average age of intervention group and control group was 16.40 years old and 16.53 years old. The average BMl of treatment group and control group was $21.76 \mathrm{~kg} / \mathrm{m}^{2}$ and $21.41 \mathrm{~kg} / \mathrm{m}^{2}$. Data result using paired sample T-test on the MMDQ of the treatment group $p=0.000(p<0.05)$ and the control group $p=0.087(p>0.05)$. NRS score of the treatment group $p=0.000$ $(p<0.05)$ and the control group $p=0.032(p<0.05)$. The results of Independent sample T-test on MMDQ and NRS showed $p=0.00(p<0.05)$. In conclusion pilates exercise can reduces the degree of primary dysmenorrhea for female student at SMA Negeri 3 Denpasar.

Keyword: menstruation, primary dysmenorrhea, pilates exercise

\section{PENDAHULUAN}

Masa remaja merupakan proses pendewasaan yang ditandai dengan berbagai perubahan seperti fisik, psikis, hormonal dan proses pematangan sistem reproduksi yang disebut pubertas. Saat mencapai usia remaja, salah satu hal yang menandakan pubertas pada perempuan yaitu menstruasi. ${ }^{1}$ Menstruasi adalah proses luruhnya dinding endometrium yang disertai dengan pendarahan oleh karena tidak terjadinya proses fertilisasi antara sel telur dan sel sperma, yang dipengaruhi oleh berbagai hormon dan terjadi pada wanita subur tidak sedang hamil maupun belum menopouse setiap bulannya. ${ }^{2}$

Salah satu gangguan yang sering muncul pada saat menstruasi yaitu dismenore. Dismenore merupakan kram atau nyeri pada perut terutama pada bagian tengah perut hingga kebawah mendekati pangkal paha dan menjalar ke punggung bagian bawah hingga area pantat. Biasanya terjadi 24 jam sebelum hingga 1-3 hari setelah menstruasi. ${ }^{3}$ Dismenore terbagi 2, yaitu dismenore primer dan dismenore sekunder. Dismenore primer adalah nyeri berupa kram spasmodik akibat peningkatan prostaglandin yang menyebabkan hiperkontraksi miometrium dan vasokonstriksi 
pembuluh darah uterus sehingga menyebabkan iskemia yang terjadi pada perempuan 1-2 tahun setelah usia menarche. Dismenore primer tidak diakibatkan oleh adanya abnormalitas maupun patologis pada pelvis. Sedangkan dismenore sekunder adalah nyeri akibat adanya kondisi patologis dan abnormalitas pada area pelvis seperti kista ovarium, endometriosis, infeksi kronis pelvis, dan patologis pelvis lainnya. Biasanya terjadi pada wanita diatas 30 tahun, sudah menikah, maupun berhubungan seksual. ${ }^{4}$ Menurut studi di Indonesia prevalensi dismenore mencapai angka $64,25 \%$, dimana 9,36\% terkena dismenore sekunder dan 54,89\% merupakan dismenore primer. ${ }^{1}$ Dalam suatu penelitian di Bali pada siswi usia 15-18 tahun pada 70 subjek dengan dismenore primer didapatkan 64,3\% mengalami nyeri dengan intensitas ringan dan 35,7\% dengan intensitas sedang. $70-90 \%$ kejadian dismenore primer akan berdampak pada kegiatan akademis dan sosial remaja. ${ }^{5}$

Terdapat beberapa hal yang merupakan faktor risiko yang dapat meningkatkan terjadinya dismenore primer yaitu, usia menarche, lamanya menstruasi, belum pernah menikah atau berhubungan seksual, Indeks Massa Tubuh, faktor psikologis, kurangnya aktifitas fisik seperti olahraga, merokok, dan riwayat keluarga atau keturunan. ${ }^{6}$

Terdapat berbagai metode yang dapat digunakan dalam mengatasi nyeri dismenore, seperti mengonsumsi obat-obatan, metode konservatif, hingga tindakan operasi. Salah satu bentuk terapi konservatif yaitu berupa sebuah terapi latihan. Latihan fisik menunjukkan hasil yang efektif untuk digunakan sebagai upaya preventif dan kuratif pada kondisi dismenore primer. ${ }^{7}$ Terdapat suatu metode terapi latihan yang dapat digunakan sebagai metode preventif dan kuratif pada kondisi dismenore primer, yaitu pilates exercise. Pilates exercise memiliki prinsip terpusat, konsentrasi, kontrol, ketelitian, mengalir, dan pernapasan. Exercise ini mampu meningkatkan mental dan kekuatan fisik yang bertujuan meningkatkan flekibilitas, kekuatan otot, koordinasi, keseimbangan, pernapasan, menghasilkan peregangan pada struktur-struktur yang terlibat, dan menurunkan kadar prostaglandin sehingga meredakan nyeri. ${ }^{8}$ Berdasarkan pemaparan diatas, peneliti menilai perlu untuk melakukan penelitian mengenai pengaruh pemberian pilates exercise terhadap penurunan derajat dismenore primer pada siswi di SMA Negeri 3 Denpasar.

\section{METODE}

Studi ini merupakan penelitian eksperimental dengan control group pre test - post test design. Telah diuji kelaikan etik oleh Komisi Etik Penelitian Fakultas Kedokteran Universitas Udayana/ RSUP Sanglah Denpasar dengan nomor 2019.01.1.1301. Penelitian ini dilaksanakan pada Januari 2020 - Juni 2020 di SMA Negeri 3 Denpasar. Pengambilan sampel menggunakan teknik non probability sampling dengan purposive sampling. Subjek penelitian sebanyak 30 sampel merupakan siswi SMA Negeri 3 Denpasar yang mengalami dismenore primer berdasarkan anamnesis pasien serta kriteria inklusi dan eksklusi. Kriteria inklusi sebagai berikut: rentang usia 15-18 tahun, selama 2 bulan terakhir memiliki mestruasi yang teratur, siklus menstruasi normal (21-35 hari), tidak mengalami cidera muskuloskeletal berat selama 6 bulan terakhir, tidak merokok, dan tidak mengonsumsi alkohol. Kriteria eksklusi sebagai berikut: menderita dismenore sekunder atau penyakit ginekologis tertentu, sampel mengkonsumsi obat pereda nyeri ketika penelitian berlangsung. Kriteria drop out sebagai berikut: tidak datang saat penelitian, responden mengundurkan diri saat penelitian.

Variabel independen pada penelitian ini adalah pilates exercise dan yang menjadi variabel dependen adalah dismenore primer. Sampel dibagi menjadi 2, yaitu kelompok perlakuan yang diberi pilates exercise dan kelompok kontrol tidak diberikan perlakuan. Pilates exercise diberikan 3x seminggu selama 3 minggu. Terdapat 15 gerakan pilates yang digunakan pada penelitian ini: Knee drop, Pelvic curl, Side to side, Single leg stretch, Stomach stretch, Double leg stretch The hundred, Single leg circles, Crisscrosser, Spine stretch, Lumbar stretch, Single leg kick, Side kick, Side leg lift, The saw. Masing masing gerakan dilakukan 10 repetisi. Derajat dismenore primer adalah tingkat keparahan dismenore primer yang dialami seseorang. Derajat dismenore primer dalam penelitian ini diukur menggunakan NRS (Numerical Rating Scale) dan MMDQ (Modified Menstrual Distress Questionnaire). NRS adalah alat ukur untuk mengetahui derajat dismenore primer berdasarkan intensitas nyeri dalam skala 0-10 yang dirasakan seseorang. Nilai 0 menyatakan "tidak nyeri", nilai 1-3 "derajat ringan", nilai 4-6 "derajat sedang", dan nilai 7-10 "derajat berat". MMDQ adalah kuisioner untuk mengetahui derajat dismenore primer berdasarkan kualitas hidup serta gangguan fungsional yang dialami seseorang selama menstruasi. MMDQ terdiri dari 31 pertanyaan dengan setiap pertanyaan dinilai dengan kriteria penilaian 0 "tidak ada gejala", 1 "gejala ringan", 2 "gejala sedang", 3 "gejala kuat", dan 4 "gejala berat". Interpretasi total skor MMDQ 0 menyatakan "tidak ada gangguan", skor 1-31 "derajat ringan", skor 32-62 "derajat sedang", skor 63-96 "derajat kuat", dan skor 97-124 "derajat berat". Subjek penelitian melakukan pre-test untuk mengukur derajat dismenore primer pada saat menstruasi sebelum melakukan penelitian dan diukur post-test pada siklus menstruasi selanjutnya setelah penelitian.

Pelaksanaan pilates exercise dalam penelitian ini dilakukan secara online dengan arahan instruktur pilates di lokasi subjek penelitian masing-masing dikarenakan wabah COVID-19. Upaya ini dilakukan untuk menjaga keselamatan dan pencegahan terkait risiko penularan COVID-19 pada subjek penelitian.

Data yang diperoleh kemudian dianalisis menggunakan SPSS 25.0 berupa: statistik deskriptif, Saphiro-wilk test untuk uji normalitas, Levene test untuk uji homogenitas, Paired sample T-test untuk perbandingan data kelompok berpasangan, dan Independent sample T-test untuk perbandingan data kelompok tidak berpasangan.

HASIL

Tabel 1. Distribusi Data Sampel Berdasarkan Usia dan IMT

\begin{tabular}{lcccc}
\hline \multirow{2}{*}{ Karakteristik } & \multicolumn{3}{c}{ Kelompok Perlakuan } & \multicolumn{2}{c}{ Kelompok Kontrol } \\
\cline { 2 - 5 } & \multicolumn{3}{c}{$(\mathrm{n}=15)$} & \multicolumn{2}{c}{$(\mathrm{n}=15)$} \\
\cline { 2 - 5 } & Mean & SD & Mean & SD \\
\hline Usia (tahun) & 16,40 & 0,910 & 16,53 & 0,915 \\
\hline IMT $\left(\mathrm{kg} / \mathrm{m}^{2}\right)$ & 21,76 & 4,11 & 21,41 & 3,26 \\
\hline
\end{tabular}


Berdasarkan data tabel 1. didapatkan bahwa sampel penelitian kelompok perlakuan memiliki rerata usia 16,40 tahun dan kelompok kontrol memiliki rerata usia 16,53 tahun. IMT kelompok perlakuan memiliki rerata $21,76 \mathrm{~kg} / \mathrm{m}^{2}$ dan kelompok kontrol memiliki rerata $21,41 \mathrm{~kg} / \mathrm{m}^{2}$. Rerata nilai IMT pada kelompok perlakuan dan kelompok kontrol terkategori normal.

Tabel 2. Hasil Uji Normalitas dan Homogenitas (skor MMDQ)

\begin{tabular}{cccccc}
\hline \multirow{3}{*}{ Kelompok Data } & \multicolumn{3}{c}{ Uji Normalitas dengan Shapiro Wilk Test } & \multirow{2}{*}{ Uji Homogenitas } \\
\cline { 2 - 5 } & \multicolumn{2}{c}{ Kelompok Perlakuan } & \multicolumn{2}{c}{ Kelompok Kontrol } & (Levene's Test) \\
\cline { 2 - 5 } & Statistik & $\mathrm{p}$ & Statistik & $\mathrm{p}$ & \\
\hline Sebelum Pelatihan & 0,205 & 0,07 & 0,152 & 0,142 & 0,315 \\
\hline Sesudah Pelatihan & 0,182 & 0,74 & 0,16 & 0,065 & 0,002 \\
\hline
\end{tabular}

Tabel 2. menunjukkan hasil uji normalitas dan homogenitas data pengukuran derajat dismenore primer menggunakan kuisioner MMDQ. Hasil uji kelompok perlakuan sebelum diberikan pilates exercise didapatkan nilai $p=0,07(p>0.05)$ dan setelah diberi pilates exercise $p=0,74(p>0,05)$, sedangkan kelompok kontrol sebelum perlakuan didapatkan nilai $p=0,142(p>0.05)$ dan setelah perlakuan nilai $p=0,065 \quad(p>0,05)$. Hasil uji normalitas tersebut menunjukkan bahwa data pengukuran skor MMDQ sebelum dan sesudah pelatihan kelompok perlakuan dan kelompok kontrol memiliki data yang berdistribusi normal.

Hasil uji homogenitas data sebelum pelatihan didapatkan nilai $p=0,315(p>0,05)$ menunjukkan data bersifat homogen dan setelah pelatihan didapatkan nilai $p=0,002(p<0,05)$ menunjukkan data bersifat tidak homogen.

Tabel 3. Hasil Uji Normalitas dan Homogenitas (skor NRS)

\begin{tabular}{cccccc}
\hline \multirow{2}{*}{ Kelompok Data } & \multicolumn{2}{c}{ Uji Normalitas dengan Shapiro Wilk Test } & \multirow{2}{*}{ Uji Homogenitas } \\
\cline { 2 - 5 } & Kelompok Perlakuan & \multicolumn{2}{c}{ Kelompok Kontrol } & (Levene's Test) \\
\cline { 2 - 5 } & Statistik & $\mathrm{p}$ & Statistik & $\mathrm{p}$ & \\
\hline Sebelum Pelatihan & 0,152 & 0,528 & 0,144 & 0,637 & 0,343 \\
\hline Sesudah Pelatihan & 0,192 & 0,235 & 0,214 & 0,192 & 0,104 \\
\hline
\end{tabular}

Tabel 3. menunjukkan hasil uji normalitas dan homogenitas data pengukuran derajat dismenore primer menggunakan NRS. Hasil uji kelompok perlakuan sebelum diberikan pilates exercise didapatkan nilai $p=0,528$ ( $p>0.05)$ dan setelah diberi pilates exercise $p=0,235(p>0,05)$, sedangkan kelompok kontrol sebelumnya didapatkan nilai $p=0,637(p>0.05)$ dan setelahnya menjadi $p=0,192(p>0,05)$. Hasil uji normalitas tersebut menunjukkan bahwa data pengukuran skor NRS sebelum dan sesudah pelatihan kelompok perlakuan dan kelompok kontrol memiliki data yang berdistribusi normal.

Hasil uji homogenitas data sebelum pelatihan didapatkan nilai $p=0,343(p>0,05)$ dan setelah pelatihan didapatkan nilai $p=0,104$ ( $p>0,05)$. Pengujian hasil pengukuran skor NRS sebelum dan sesudah pelatihan menunjukkan data bersifat homogen. Berdasarkan hasil tersebut, maka digunakan uji statistik parametrik dalam penelitian ini.

Tabel 4. Perbedaan Derajat Dismenore Primer Sebelum dan Sesudah Pelatihan (Skor MMDQ) Uji Paired Samples T-test

\begin{tabular}{cccccc} 
Kelompok Data & \multicolumn{3}{c}{ Sebelum Pelatihan } & \multicolumn{3}{c}{ Sesudah Pelatihan } & \multirow{2}{*}{$p$-value } \\
\cline { 2 - 5 } & Mean & SD & Mean & SD & \\
\hline Kelompok Perlakuan & 37,80 & 11,7 & 23,20 & 6,67 & 0,000 \\
\hline Kelompok Kontrol & 42,27 & 18,22 & 36,20 & 13,61 & 0,087 \\
\hline
\end{tabular}

Berdasarkan tabel 4. menunjukkan hasil perbedaan rerata penurunan derajat dismenore primer sebelum dan sesudah pelatihan kelompok perlakuan serta kelompok kontrol dengan data pengukuran menggunakan kuisioner MMDQ. Menurut hasil analisis diatas diketahui kelompok perlakuan yang awalnya memiliki rerata derajat dismenore primer sebesar $37,80 \pm 11,7$ terkategori derajat sedang dan setelah diberikan intervensi pilates exercise menurun menjadi $23,20 \pm 6,67$ terkategori derajat ringan dengan nilai $p=0,000(p<0,05)$ yang artinya adanya perbedaan yang signifikan pada penurunan derajat dismenore primer sebelum dan sesudah diberikan pilates exercise pada siswi di SMA Negeri 3 Denpasar.

Pada hasil analisis kelompok kontrol yang awalnya memiliki rerata derajat dismenore primer sebesar $42,27 \pm 18,22$ terkategori derajat sedang dan setelahnya menurun menjadi 36,20 $\pm 13,6$ terkategori derajat sedang dengan nilai $p=0,087(p>0,05)$ artinya tidak terdapat perbedaan yang signifikan dalam penurunan derajat dismenore primer pada kelompok kontrol.

Tabel 5. Perbedaan Derajat Dismenore Primer Sebelum dan Sesudah Pelatihan (Skor NRS)

$$
\text { Uji Paired Samples T-test }
$$

\begin{tabular}{cccccc}
\multirow{2}{*}{ Kelompok Data } & \multicolumn{3}{c}{ Sebelum Pelatihan } & \multicolumn{3}{c}{ Sesudah Pelatihan } & \multirow{2}{*}{ p-value } \\
\cline { 2 - 5 } & Mean & SD & Mean & SD & \\
\hline Kelompok Perlakuan & 5,13 & 1,45 & 2,67 & 1,11 & 0,000 \\
\hline Kelompok Kontrol & 5,20 & 1,82 & 4,33 & 1,49 & 0,032 \\
\hline
\end{tabular}

Berdasarkan tabel 5. menunjukkan hasil perbedaan rerata penurunan derajat dismenore primer kelompok perlakuan dan kelompok kontrol sebelum dan sesudah pelatihan dengan data pengukuran menggunakan NRS. Menurut hasil analisis diatas diketahui kelompok perlakuan yang awalnya memiliki rerata derajat dismenore primer sebesar $5,13 \pm 1,45$ terkategori derajat sedang dan setelah diberikan intervensi pilates exercise menurun menjadi $2,67 \pm 1,11$ terkategori derajat ringan dengan nilai $p=0,000(p<0,05)$ artinya adanya perbedaan yang signifikan dalam 
penurunan derajat dismenore primer sebelum dan sesudah diberikan pilates exercise pada siswi di SMA Negeri 3 Denpasar.

Pada hasil analisis kelompok kontrol yang awalnya memiliki rerata derajat dismenore primer sebesar 5,20 $\pm 1,82$ terkategori derajat sedang dan setelahnya menurun menjadi 4,33 $\pm 1,49$ terkategori derajat sedang dengan $p=0,032$ $(p<0,05)$ artinya terdapat perbedaan yang signifikan dalam penurunan derajat dismenore primer pada kelompok kontrol.

Tabel 6. Hasil Uji Pengaruh Pilates Exercise Terhadap Derajat Dismenore Primer (Skor MMDQ)

\begin{tabular}{|c|c|c|c|c|c|}
\hline \multirow{3}{*}{ Kelompok Data } & \multicolumn{4}{|c|}{ Uji Independent T-test } & \multirow{3}{*}{$p$-value } \\
\hline & \multicolumn{2}{|c|}{ Kelompok Perlakuan } & \multicolumn{2}{|c|}{ Kelompok Kontrol } & \\
\hline & Mean & SD & Mean & SD & \\
\hline Sebelum Pelatihan & 37,80 & 11,7 & 42,27 & 18,22 & 0,43 \\
\hline Sesudah Pelatihan & 23,20 & 6,67 & 36,20 & 13,61 & 0,00 \\
\hline
\end{tabular}

Tabel 7. Hasil Uji Pengaruh Pilates Exercise Terhadap Derajat Dismenore Primer (Skor NRS)

\begin{tabular}{|c|c|c|c|c|c|}
\hline \multirow{3}{*}{ Kelompok Data } & \multicolumn{4}{|c|}{ Uji Independent T-test } & \multirow[b]{2}{*}{$p$-value } \\
\hline & \multicolumn{2}{|c|}{ Kelompok Perlakuan } & \multicolumn{2}{|c|}{ Kelompok Kontrol } & \\
\hline & Mean & SD & Mean & SD & \\
\hline Sebel & 5,13 & 1,45 & 5,20 & 1,82 & 0,91 \\
\hline Sesudah & 2,67 & 1,11 & 4,33 & 1,49 & 0,00 \\
\hline
\end{tabular}

Berdasarkan tabel 6 dan tabel 7 nilai $p$ uji Independent Samples T-test pada ke dua kelompok sebelum pelatihan menunjukkan $p=0,43(p>0,05)$ dan $p=0,91(p>0,05)$ artinya tidak terdapat perbedaan yang signifikan antara nilai sebelum pelatihan kelompok perlakuan dan kelompok kontrol, dimana ke dua kelompok berawal dari kategori yang sama.

Uji Independent Samples $T$-test setelah pelatihan untuk mengetahui pengaruh pilates exercise terhadap derajat dismenore primer menunjukkan nilai $p=0,00(p<0,05)$ pada ke dua kelompok setelah pelatihan, dimana secara statistik dapat diartikan bahwa adanya perbedaan yang signifikan antara kelompok perlakuan dan kelompok kontrol setelah pelatihan. Sehingga hipotesis penelitian ini dapat diterima yaitu pemberian pilates exercise menurunkan derajat dismenore primer pada siswi di SMA Negeri 3 Denpasar.

\section{DISKUSI}

\section{Karakteristik Sampel Penelitian}

Rentang usia subjek penelitian ini berkisar dari 15-18 tahun. Rerata usia pada kelompok perlakuan adalah $16,40 \pm 0,91$ tahun dan pada kelompok kontrol 16,53 $\pm 0,91$ tahun. Karakteristik sampel menunjukan rerata usia kedua kelompok relatif sama. Bertambahnya usia menurunkan angka terjadinya dismenore primer dan akan berkurang saat mencapai usia 30 tahun maupun melahirkan. Wanita remaja memiliki prevalensi lebih tinggi mengalami dismenore primer dibandingkan wanita dewasa. Prevalensi wanita yang mengalami dismenore $25 \%-50 \%$ terjadi pada wanita dewasa, sedangkan pada wanita remaja menunjukkan angka yang lebih tinggi yaitu $75 \% .{ }^{9} \mathrm{Hal}$ ini dikarenakan semakin bertambahnya usia wanita, maka akan semakin sering seseorang mengalami menstruasi dan uterusnya semakin lebar yang akan menyebabkan sekresi hormon prostaglandin berkurang. Penuaan akan berdampak terhadap penurunan fungsi saraf rahim yang menurunkan risiko dismenore primer. ${ }^{6}$

Hasil perhitungan IMT pada kelompok perlakuan memiliki rerata $21,76 \pm 4,11 \mathrm{~kg} / \mathrm{m}^{2}$ dan kelompok kontrol $21,41 \pm 3,26 \mathrm{~kg} / \mathrm{m}^{2}$. Rerata nilai IMT pada kelompok perlakuan dan kelompok kontrol terkategori normal. Studi pada remaja usia 12-18 tahun menyatakan adanya hubungan yang signifikan dengan $p<0,001$ antara IMT underweight terhadap prevalensi terjadinya dismenore primer. ${ }^{10} \mathrm{Hal}$ ini dikarenakan rendahnya status nutrisi dan asupan makan yang buruk yang mengganggu terhadap sekresi kelenjar pituitari hormon gonadotropin sehingga meningkatkan terjadinya dismenore primer. ${ }^{11}$ Penelitian lain juga menyatakan IMT overweight merupakan faktor risiko terjadinya dismenore primer. Hal ini karena jaringan lemak pada orang dengan kelebihan berat badan dapat menyebabkan terdesaknya pembuluh darah oleh jaringan lemak atau hiperplasi pembuluh darah sehingga menyebabkan terganggunya aliran darah pada proses menstruasi. ${ }^{12}$ Penelitian lain menyatakan tingginya lemak pada pinggangpinggul berpengaruh terhadap kejadian dismenore primer. Hal ini karena dapat menurunkan tingkat sirkulasi hormon estrogen yang berperan dalam meregulasi akumulasi lemak pada perut, pinggul dan paha. Jika terjadi gangguan keseimbangan hormon estrogen akan berdampak terhadap metabolisme hormon progesteron yang menyebabkan terjadinya peningkatan prostaglandin, kontraksi miometrium dan iskemia dinding rahim sehingga terjadinya nyeri dismenore primer. ${ }^{13}$

\section{Pemberian Pilates Exercise Menurunkan Derajat Dismenore Primer}

Berdasarkan hasil paired sample $t$-test yang digunakan untuk mengetahui penurunan derajat dismenore primer dengan data pengukuran menggunakan kuisioner MMDQ pada kelompok kontrol, menunjukkan nilai $p=0,087(p>0,05)$ yang artinya tidak terdapat perbedaan yang signifikan pada penurunan derajat dismenore primer kelompok kontrol. Sedangkan pada kelompok perlakuan dengan pengukuran menggunakan kuisioner MMDQ dan data pengukuran menggunakan NRS, menunjukkan nilai $p=0,000(p<0,05)$ yang artinya adanya perbedaan yang signifikan terhadap penurunan derajat dismenore primer sebelum dan sesudah diberikan pilates exercise pada siswi di SMA Negeri 3 Denpasar. Berdasarkan hasil uji Independent $t$-test data pengukuran menggunakan MMDQ dan NRS diperoleh nilai $p=0,00(p<0,05)$ diartikan bahwa adanya perbedaan yang signifikan antara kelompok perlakuan dan kelompok kontrol dalam penurunan derajat dismenore primer pada siswi di SMA Negeri 3 Denpasar. 
Pilates exercise dapat memberikan efek analgesik dengan meningkatkan pain threshold dalam endogenous pain control mechanism karena tubuh akan mensekresikan neurotransmitter seperti serotonin, norepinephrine, encephalins, dan dopamine lebih banyak untuk dapat menginhibisi dan mengontrol nyeri. Saat melakukan pilates exercise maka akan terjadi peningkatan aliran darah kebagian organ-organ pelvis, meningkatkan elastisitas otot, dan peregangan pada struktur-struktur yang terlibat sehingga mempengaruhi peningkatan kadar oksigen pada setiap organ agar tercukupi dengan maksimal dan tidak terjadinya iskemia. ${ }^{14}$

Pilates exercise juga dapat meningkatkan tingkat sirkulasi endorphin. Pilates exercise merangsang otak untuk mensekresi hormon endorphin kedalam darah hingga empat sampai lima kali dan menaikkan pain threshold. Endorphin diproduksi oleh kelenjar pituitari yang berfungsi sebagai penurun rasa sakit alami dari tubuh. Meningkatnya kadar endorphin pada pemberian pilates exercise akan menurunkan prostaglandin di dalam darah. ${ }^{15}$ Ketika melakukan pilates exercise, endorphine akan disekresikan dan ditangkap oleh reseptor di dalam hipotalamus dan sistem limbik. Ketika neuron perifer mengirim sinyal ke sinaps, terjadi ikatan reseptor opioid $\mu$ di pre dan post sinaps tempat seharusnya substansi $\mathrm{P}$ akan menghantarkan impuls. Substansi $\mathrm{P}$ merupakan neurotransmitter yang berfungsi mentransmisi impuls nyeri dari perifer ke otak. Endorphin dan neurotransmitter penghambat impuls nyeri akan mengalir di dalam darah dan menghambat mediator-mediator biokimia seperti prostaglandin dan substansi $P$. Sehingga penghantaran impuls nyeri di medulla spinalis menjadi terhambat dan korteks serebri tidak menerima sinyal nyeri, dengan demikian intensitas nyeri dismenore primer akan berkurang. ${ }^{16}$

Dismenore primer menimbulkan nyeri pada perut terutama pada bagian tengah perut hingga kebawah mendekati pangkal paha dan menjalar ke punggung bagian bawah sehingga menyebabkan LBP (low back pain). Berdasarkan kuisioner sebagian besar sampel mengeluhkan nyeri punggung bawah saat menstruasi. Metode pilates exercise mendukung dalam mengatasi LBP dimana kelemahan otot core merupakan salah satu faktor risiko terjadinya LBP. Penelitian menunjukkan tidak optimalnya kerja otot transversus abdominis, abdominal oblique, multifidus, dan diaphragm berpengaruh terhadap munculnya LBP. ${ }^{17}$ Penelitian Sekendiz, et al. 2007 menyatakan pilates exercise merupakan latihan yang efektif dalam meningkatkan kekuatan otot abdominal dan lower back, fleksibilitas posterior trunk, dan abdominal muscular endurance pada wanita. Gerakan pilates the hundreds, roll-up, dan leg cicle menunjukkan hasil yang positif dalam meningkatkan serat otot dan spinal stabilization pada otot trasversus abdominis dan obliquus internus abdominis pada saat melakukan pilates exercise. ${ }^{18}$ Penelitian pada wanita dengan LBP menyatakan pilates exercise mampu menurunkan level nyeri yang dirasakan serta meningkatkan kualitas hidup. ${ }^{14}$

\section{SIMPULAN}

Berdasarkan analisis data hasil penelitian yang telah dilakukan serta pembahasan, didapatkan kesimpulan bahwa pemberian pilates exercise menurunkan derajat dismenore primer pada siswi di SMA Negeri 3 Denpasar.

\section{DAFTAR PUSTAKA}

1. Wahyuni. The Effect Of Pilates Exercise To Hamper Primary Dysmenorrhea In 18-21 Years Old Adolescents. International Conference on Health and Well-Being. Surakarta: Universitas Muhammadiyah Surakarta; 2016

2. lacovides S, Avidon I, Bentley A, Baker F C. Diclofenac Potassium Restores Objective and Subjective Measures of Sleep Quality in Women with Primary Dysmenorrhea. 2009; 32(8): 1019-1026. doi:10.1093/sleep/32.8.1019

3. Weisman A M, Hartz A J. The natural history of primary dysmenorrhoea: a longitudinal. BJOG: An International Journal of Obstetrics \& Gynaecology. 2009; 111: 345-352

4. Charu S, Amita R, Sujoy R, Aneesh G. Menstrual characteristics' and 'Prevalence and Effect of Dysmenorrhea' on Quality of Life of medical student. International Journal of Collaborative Research on Internal Medicine \& Public Health. 2012; 4(4): 276-294

5. Puji. Efektifitas Senam Dismenorea Dalam Mengurangi Dismenorea pada Remaja Putri di SMUN 5 Semarang. [skripsi]. Semarang:Universitas Diponegoro; 2011 [diakses pada 13 juli 2018]. Tersedia di: http://eprints.undip.ac.id

6. Novia I, Puspitasari N. Faktor Risiko yang Mempengaruhi Kejadian Dismenore Primer. Indonesia Jurnal Of Public Health. 2008;4(2):96-104

7. Brukner P, Khan K. Brukner \& Khan's clinical sports medicine. McGraw-Hill Australia Pty Ltd. Australia: 2012

8. Elfira R, Saadah S, Rismawari S. Pengaruh Pilates Exercise Terhadap Nyeri Primary Dysmenorrhea Pada Siswi Di Smkn Sukaresik Kabupaten Tasikmalaya Tahun 2017. Jurnal Kesehatan Bakti Tunas Husada. 2017; 17(2): 293302

9. Latthe P M, Champaneria R. Dysmenorrhoea. BMJ clinical evidence, 2011.

10. Chauhan M, Kala J. Relation between dysmenorrhea and body mass index in adolescents with rural versus urban variation. The Journal of Obstetrics and Gynecology of India. 2012; 62(4): 442-445.

11. Singh A, Kiran D, Singh H, Nel B, Singh P, Tiwari P. Prevalence and severity of dysmenorrhea: a problem related to menstruation, among first and second year female medical students. Indian J Physiol Pharmacol. 2008; 52(4): 389-397.

12. Wahyuni R S, Oktaviani W. Hubungan Indeks Massa Tubuh dengan Dismenore pada Remaja Putri SMP PGRI Pekanbaru. Jurnal Endurance. 2018; 3(3): 618-623.

13. Ardiyastin M. Hubungan Rasio Lingkar Pinggang-Panggul Terhadap Tingkat Nyeri Menstruasi Primer Pada Remaja Perempuan.[skripsi]. Denpasar: Fakultas Kedokteran Universitas Udayana; 2018: 45-46.

14. Araujo, de Luana Macedo, Jose Mario Nunes da Silva, Weltianne Tavares Bastos, Patricia Lima Ventura. Pain improvement in women with primary dysmenorrhea treated by Pilates. Rev Dor. 2012; 13(2): 119-23.

15. Kumalasari M LF. The Effectiviness of Dysmenorrhea Gymnastics as an Alternative Therapy in Reducing Menstrual Pain. Journal of Health Science and Prevention. 2017; 1(1):10-14.

16. Murtiningsih $M$, Maelani $M$, Fitriani $H$. Teknik mengurangi dismenore primer dengan olahraga. Jurnal ilmu 
keperawatan maternitas. 2018; 1(2): 24-30.

17. Sorosky S, Stilp S, Venu Akuthot V. Yoga and Pilates in the management of low back pain. Curr Rev Musculoskelet Med. 2008;1:39-47. DOI 10.1007/s12178-1007-9004-1

18. Endleman I, Critchley D J. Transversus abdominis and obliquus internus activity during pilates exercises: measurement with ultrasound scanning. Archives of physical medicine and rehabilitation. 2008; 89(11): 2205-2212. 